2013-05-05

\title{
Stress Distribution at the Bone-Cement Interface Changes During Kyphoplasty Rehabilitation
}

\author{
Philip Purcell \\ Technological University Dublin, philip.purcell@tudublin.ie \\ Stephen Tiernan \\ Technological University Dublin, stephen.tiernan@tudublin.ie \\ Fiona McEvoy \\ Technological University Dublin
}

See next page for additional authors

Follow this and additional works at: https://arrow.tudublin.ie/ittengoth

Part of the Engineering Commons

\section{Recommended Citation}

Purcell, P., Tiernan, S., McEvoy, F., Tyndyk, M. and Morris, S. Stress distribution at the bone-cement interface changes during Kyphoplasty rehabilitation. 29th Southern Biomedical Engineering Conferece 2013, Miami, USA

This Conference Paper is brought to you for free and open access by the School of Engineering at ARROW@TU Dublin. It has been accepted for inclusion in Other Resources by an authorized administrator of ARROW@TU Dublin. For more information, please contact arrow.admin@tudublin.ie, aisling.coyne@tudublin.ie, gerard.connolly@tudublin.ie. Funder: Irish Research Council

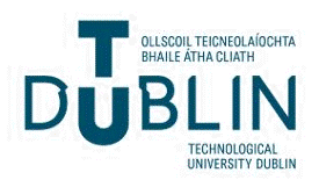




\section{Authors}

Philip Purcell, Stephen Tiernan, Fiona McEvoy, Magdalena Tyndyk, and Seamus Morris 


\title{
Stress distribution at the bone-cement interface changes during Kyphoplasty rehabilitation
}

\author{
Philip Purcell, Magdalena Tyndyk, Fiona McEvoy, Stephen Tiernan and Seamus Morris
}

\begin{abstract}
Balloon Kyphoplasty uses an inflatable bone tamp and cement augmentation to repair vertebral compression fractures. A recent clinical study observed a $\mathbf{7 8 \%}$ re-collapse rate in patients showing a radiolucent phenomenon at the bonecement interface following Kyphoplasty. Two experimental studies showed significant height loss following Balloon Kyphoplasty under cyclical loads. The present study investigates the alteration in load angle corresponding to this height loss and its effect on load transfer to the bone-cement interface. A validated finite element model of a human thoracolumbar spine was segmented into a single $\mathrm{L} 1$ vertebral body and modified to replicate bilateral Balloon Kyphoplasty. Cement was modeled using prolate spheroids surrounded by an interface region divided into anterior, middle and posterior sections. Interface thickness was calculated using a mathematical model with a bone volume fraction of 0.3 and $50 \%$ bone compaction. An $800 \mathrm{~N}$ load was applied at angles of $0^{\circ}$ and $20^{\circ}$ from the vertebral axis. Results indicate that a change in the applied load angle significantly alters the principal stress components and directions across the interface region. This alteration in loading must be considered in the context of the highly compliant interface region and therefore is hypothesized to be a contributory factor to vertebral recollapse.
\end{abstract}

\section{INTRODUCTION}

Treating fractures of the spine is a major challenge for the medical community both within Ireland and the US with an estimated 1.4 million fractures per annum worldwide [1]. It has been estimated that approximately $15 \%$ [2] of spinal injuries are associated with trauma events, while the remainder are classified as insufficiency fractures related to poor bone quality. An Irish study [3] of $\sim 1,000$ admissions during a 5-year period found traumatic spinal injuries needed on average 46 days of hospital admission along with life-long monitoring in cases of spinal cord injury. Costs for life-long treatment of a 25 -year old with spinal cord injury in the United States has been estimated at $\$ 4.5$ million [4].

A recent clinical study [5] of 175 patients drew attention to a radiological halo phenomenon around the bone-cement interface following Kyphoplasty. The authors statistically correlated this radiological feature with a $78 \%$ re-collapse rate and attributed the phenomenon to a lack of cement

*Research funded by the Irish Research Council EMBARK postgraduate scholarship awarded to lead author Philip Purcell.

Philip Purcell is a postgraduate student supervised by Fiona McEvoy and Stephen Tiernan at the Centre of Applied Science for Health, Institute of Technology Tallaght, Tallaght, Dublin 24, Ireland. (phone:+35314042958; fax:+35314042504; e-mail: philip.purcell@ittd.ie).

Magdalena Tyndyk, is the research coordinator at the Medical Engineering Design Innovation Centre, Cork Institute of Technology, TYCO Building, 53 Melbourne Road, Bishopstown, Cork, Ireland.

Seamus Morris is a consultant orthopedic surgeon in the National Spinal Injuries Unit at Mater Misericordiae University Hospital, Eccles St., Dublin 7, Ireland. interdigitation into the trabecular structure. A recent in-vitro study [6] confirmed cement infiltration and mechanical interlock was restricted following Kyphoplasty due to the presence of compacted bone. Two studies [7,8] involving cyclical loading of Kyphoplasty treated vertebrae showed statistically significant height losses over the course of 100,000 loading cycles to replicate the rehabilitation period.

The current work hypothesizes that mechanical loading at the bone-cement interface is altered by the changing load angle induced by vertebral height loss. The authors propose that this change in loading of the compacted bone-cement interface is a significant factor in instigating further vertebral collapse.

\section{METHODS}

A validated finite element model [9] of a human thoracolumbar spine was segmented into a single L1 vertebral body and modified to replicate bilateral Balloon Kyphoplasty. The first lumbar vertebra was selected for analysis since it is commonly fractured in injuries to the spinal column [10]. Cement was modeled using prolate spheroids surrounded by an interface region divided into anterior, middle and posterior sections. Interface thickness was calculated using a previously developed [11] mathematical model with a bone volume fraction of 0.3 and $50 \%$ bone compaction [12]. An $800 \mathrm{~N}$ [13] load was applied at angles of $0^{\circ}$ and $20^{\circ} \quad[14]$ to represent the loading conditions during rehabilitation after the Kyphoplasty procedure.

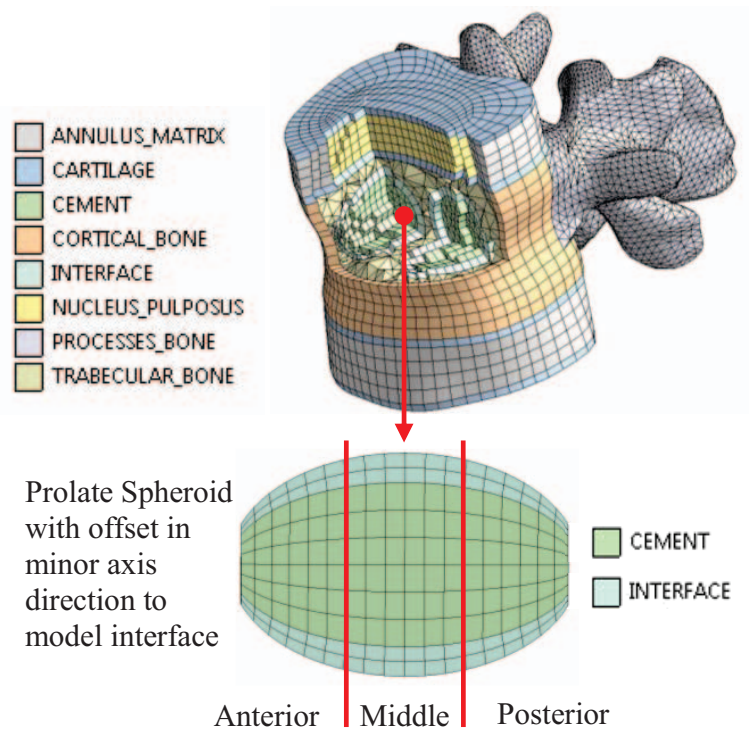

Figure 1. Finite element model of bi-lateral Kyphoplasty in L1 vertebra. 


\section{RESULTS}

Results indicate that increased Kyphotic loading causes a shift in stress distribution to the posterior parts of the interface region by up to $34-44 \%$. The anterior and middle sections of the interface experienced changes in average Von Mises stress of less than 11\%. Maximum Von Mises stresses were not strongly influenced by the altered loading angle and increased by up to $7 \%$ in the posterior section of the interface region.

\section{\% Change in average Von Mises stress} after increasing load angle to $20^{\circ}$

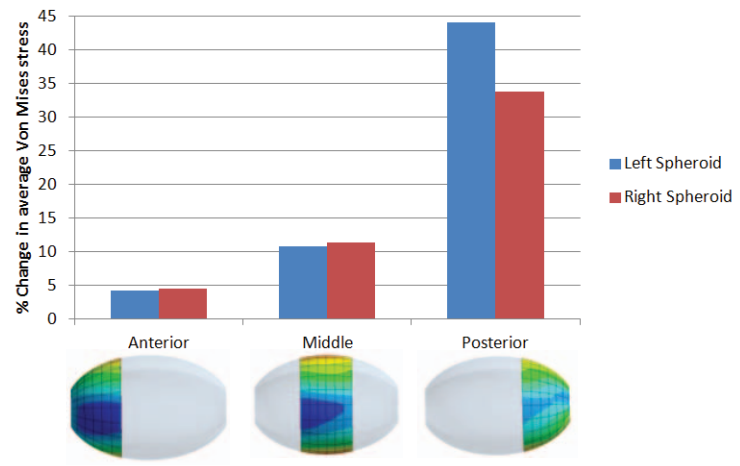

Figure 2. Graph of percentage change in average Von Mises stress after increasing the applied load angle to $20^{\circ}$.

\section{DISCUSSION \& ANALYSIS}

Recent literature evaluating Balloon Kyphoplasty postoperatively have indicated significant height loss and vertebral re-collapse in patients exhibiting a bone-cement halo phenomenon on radiographs [5]. The results from the current study show that height loss induced load changes initiate a shift in stress distribution to the posterior parts of the interface region. Further investigation of the stress states found significant compressive stresses are imposed on the posterior parts of the interface region due to the transmission of shear loads through the pedicles caused by Kyphosis. These results show that height loss and interface loading are strongly interdependent and can contribute to sustaining a cycle of increased interfacial stresses leading to further vertebral collapse.

Applying these findings in the context of Kyphoplasty, where poor cement interdigitation is prevalent [6], indicates an increased likelihood of sliding at the contact points between the bone and cement. It has been shown [15] that localized deformation at bone-cement contact sites constitute a significant proportion of the deformation seen in the interface region. The increased loading in the posterior parts of the interface carries additional significance in a clinical context since the cement bolus in this region often contains an imprint from the cannula used by the surgeon.
This cannula defect creates a site for crack initiation in the cement mantle which has been observed during a fatigue study [7] of Kyphoplasty with calcium phosphate cement.

\section{CONCLUSION}

The results from the current work indicate that the design of medical procedures and devices to treat vertebral compression fractures must focus on achieving a strong mechanical interlock between the augmentation medium and the native bone to ensure the longevity of the treatment.

\section{ACKNOWLEDGMENT}

Funded by the Irish Research Council EMBARK postgraduate scholarship awarded to Philip Purcell.

\section{REFERENCES}

[1] Johnell O, Kanis JA. An estimate of the worldwide prevalence and disability associated with osteoporotic fractures. Osteoporosis Int 2006;17(12):1726-33.

[2] Denis F. Spinal instability as defined by the three-column spine concept in acute spinal trauma. Clin Orthop Relat $R$ 1984;(189):6576.

[3] Lenehan B, Boran S, Street J, Higgins T, McCormack D, Poynton AR. Demographics of acute admissions to a National Spinal Injuries Unit, Eur Spine J 2009;18(7):938-42.

[4] NSCISC. Spinal cord injury facts and figures at a glance. J Spinal Cord Med 2012 Nov;35(6):480-1.

[5] Kim KHS, Kuh SU, Park JY, Chin DK, Cho YE. What is the importance of "halo" phenomenon around bone cement following vertebral augmentation for osteoporotic compression fracture? Osteoporosis Int 2012;23(10):2559-65.

[6] Krüger A, Oberkircher L, Kratz M, Baroud G, Becker S, Ruchholtz S. Cement interdigitation and bone-cement interface after augmenting fractured vertebrae: A cadaveric study. ISASS 2012;6(1):115-123.

[7] Wilke H-J, Mehnert U, Claes LE, Bierschneider MM, Jaksche H, Boszczyk BM. Biomechanical evaluation of vertebroplasty and kyphoplasty with polymethyl methacrylate or calcium phosphate cement under cyclic loading. Spine 2006;31(25):2934-41.

[8] Kim MJ, Lindsey DP, Hannibal M, Alamin TF. Vertebroplasty versus kyphoplasty: biomechanical behavior under repetitive loading conditions. Spine 2006;31(18):2079-84.

[9] Tyndyk M., Barron V, McHugh PE, O’Mahoney D. Generation of a finite element model of the thoracolumbar spine. Acta Bioeng Biomech 2007;9(1):35-46.

[10] Maestretti G, Cremer C, Otten P, Jakob RP. Prospective study of standalone balloon kyphoplasty with calcium phosphate cement augmentation in traumatic fractures. Eur Spine J 2007;16(5):601-10.

[11] Purcell P, Tyndyk M, McEvoy F, Tiernan S, Morris S. A novel method for computational modeling of compacted bone following Balloon Kyphoplasty. Institution of Mechanical Engineers \& Engineers Ireland, Young Research Engineer Award 2012.

[12] Purcell P, McEvoy F, Tiernan S, Morris S. Experimental quantification of the compacted zone in a synthetic bone model treated using Balloon Kyphoplasty. Proceedings of the $19^{\text {th }}$ Annual Conference of the Section of Bioengineering of the Royal Academy of Medicine in Ireland, Jan $18^{\text {th }}-19^{\text {th }} 2013$, Johnstown House Hotel.

[13] Tyndyk M., Finite element modelling of the mechanical behavior of the thoracolumbar spine. PhD Thesis, National University of Ireland Galway, 2005.

[14] Aquarius R, Homminga J, Verdonschot N, Tanck E. The fracture risk of adjacent vertebrae is increased by the changed loading direction after a wedge fracture. Spine 2011;36(6):E408-12.

[15] Zhao Y, Robson Brown KA, Jin ZM, Wilcox RK. Trabecular Level Analysis of Bone Cement Augmentation: A Comparative Experimental and Finite Element Study. Ann Biomed Eng 2012;40(10):2168-76 